\title{
Systematic Review on the Efficacy of Fexofenadine in Seasonal Allergic Rhinitis: A Meta-Analysis of Randomized, Double-Blind, Placebo-Controlled Clinical Trials
}

\author{
E. Compalati ${ }^{a} \quad$ R. Baena-Cagnani ${ }^{b, c}$ M. Penagos ${ }^{a} \quad$ H. Badellino ${ }^{b, c}$ F. Braido ${ }^{a}$ \\ R.M. Gómez ${ }^{c}$ G.W. Canonica ${ }^{a}$ C.E. Baena-Cagnani ${ }^{a-c}$
}

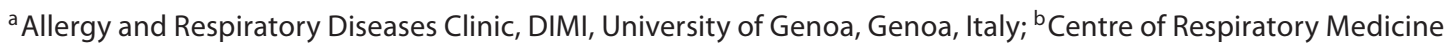
and Allergy, Chutro Clinic, and ${ }^{\mathrm{C} C I M E R}$, Centre for Investigation in Respiratory Medicine, Faculty of Medicine, Catholic University of Cordoba, Cordoba, Argentina

\section{Key Words}

Fexofenadine - Allergic rhinitis • Antihistamines •

Meta-analysis $\cdot$ Evidence-based medicine

\begin{abstract}
Rationale: Evidence-based medicine represents the effort to highlight the best intervention for patients, clinicians, and policy makers, each from their respective viewpoint, to solve a particular health condition. According to a recently diffused grading system of evidence and recommendations for medical interventions, efficacy and safety represent 2 of the most important features to consider, and data from metaanalyses of randomized controlled clinical trials (RCTs) is the strongest supporting demonstration. Fexofenadine has been used for its efficacy and safety in the treatment of allergic rhinitis (AR) for many years although no meta-analyses supporting its use currently exist. The aim of this study is to assess for the first time the efficacy and safety of fexofenadine in the treatment of AR by means of a meta-analytic analysis of existing RCTs. Since specific evidence should be provided to address recommendations in a pediatric population, the quality of the estimates of this subgroup analysis is assessed. Methods: All double-blind, placebo-controlled randomized trials assessing the efficacy of fexofenadine in
\end{abstract}

AR were searched for in OVID, Medline, and Embase databases up to December 2007. Outcomes were extracted from original articles; when this information was not available, the authors of each trial were contacted. Some graphics were digitalized. The RevMan 5 program was used to perform the analysis. GradePro 3.2.2 was used to assess the quality of the evidence for a pediatric population. Results: Of 2,152 identified articles, 20 were potentially relevant trials. Eight studies satisfied the inclusion criteria and were included in the meta-analysis. The main reasons for exclusion were: unnatural exposure, strong study limitations, an atypical outcome measurement, a design for other outcomes, and not being a placebo-controlled, single-blind study. Seven trials investigated a mixed population of adults and children, 1 trial investigated only children, and 1 trial only adults. In 1,833 patients receiving fexofenadine (1,699 placebo), a significant reduction of the daily reflective total symptom scores (TSS) (SMD - $0.42 ; 95 \% \mathrm{Cl}-0.49$ to $-0.35, \mathrm{p}<0.00001$ ) was found. Positive results were also found for morning instantaneous

In the last 5 years, Prof. Carlos Baena-Cagnani received clinical research support and speaker's honoraria while Dr. Martin Penagos received a research grant from Sanofi-Aventis. ARMIA and LIBRA are nonprofit research foundations supported by private donors.

\section{KARGER}

Fax +41613061234 E-Mail karger@karger.ch www.karger.com
(C) 2011 S. Karger AG, Basel $1018-2438 / 11 / 1561-0001 \$ 38.00 / 0$

Accessible online at:

www.karger.com/iaa
Correspondence to: Prof. Carlos E. Baena-Cagnani

Centre of Respiratory Medicine and Allergy, Chutro Clinic

Santa Rosa 381

5000 Cordoba (Argentina)

Tel. +54 351423 0886, Fax +54 351425 9644, E-Mail cebaenac@ fundacionlibra.org 
TSS and individual nasal symptom scores (sneezing, rhinorrhea, itching, and congestion). The safety analysis did not show a significant difference in reported adverse events (AE) between the active and placebo treatment groups (OR = $1.03 ; 95 \% \mathrm{Cl} 0.87-1.22, \mathrm{p}=0.75)$. A very low heterogeneity between the studies was detected, so a fixed-effects model was used. The mean quality level of the included trials was medium. Specific information for a pediatric population may be assumed with a moderate quality of evidence from only 1 study and with a low quality of evidence, mainly due to indirectness, from the others. Conclusions: This study has 5 major strengths: it represents the first attempt to evaluate the efficacy and safety of fexofenadine in the treatment of AR by means of a meta-analysis of RCTs; there was consistency between positive results in terms of efficacy in TSS and in individual symptoms; a large population was studied; there was an irrelevant interstudy heterogeneity, and the $A E$ frequency was similar in both groups. All of these values encourage the recommendation of fexofenadine for AR. Further research focused on the benefits and disadvantages for a pediatric population is needed.

Copyright $\odot 2011$ S. Karger AG, Basel

\section{Introduction}

Allergic rhinitis (AR) is an inflammatory disorder of the nose induced by allergen exposure. It is clinically characterized by 4 main symptoms: rhinorrhea, itching, sneezing, and nasal obstruction [1]. A high percentage (42\%) of patients with AR, typically patients with seasonal pollinosis, also have symptoms of allergic conjunctivitis [2]. The immunopathology of AR recognizes a sensitization phase in which allergens penetrating the epithelial layer of the respiratory tract are processed by antigen-presenting cells and presented to histocompatibility complex molecules resulting in the development of specific $\mathrm{T}$ cell clones, followed by the production of allergen-specific IgE from plasma cells. Any further contact with allergen leads to a fast IgE-mediated response characterized by the degranulation of mast cells and basophils with a release of preformed and newly synthesized mediators which are able to provoke the typical symptoms of rhinitis within minutes. Histamine is the major mediator of the early-phase reaction; it stimulates sensory nerves, causing sneezing and itching, and it is responsible for vasodilation, plasma exudation, and the stimulation of mucous cells leading to rhinorrhea and nasal obstruction. A late-phase reaction occurs a few hours after allergen exposure and is associated with cellular eosinophilic inflammation of the nasal mucosa and expression of endothelial and epithelial adhesion molecules, chemokines, and cytokines [3].

Traditionally, the disease has been classified as seasonal, perennial, or occupational AR. Nevertheless, this approach was revised in the recent ARIA guidelines which focused more on patients' symptoms than on the time of year in which they occur. This validated an everyday practice classification which, on the basis of the chronicity of symptoms, distinguishes intermittent AR $(<4$ days per week or $<4$ weeks per year) from persistent AR ( $>4$ days per week and $>4$ weeks per year) [4].

Nasal symptoms are often trivialized but they can lead to a significant reduction in the quality of life (QoL) of patients and their families, with a negative impact on work productivity, school performance, and social activities. The total burden of this disease also lies in a financial strain which is made greater when considering the evidence that $\mathrm{AR}$ is a possible causal factor in comorbid diseases such as asthma and sinusitis; in this context, both direct (health care resource utilization and drug costs) and indirect costs (loss of productivity) should be considered [5]. Nasal congestion, one of the most prominent symptoms in $\mathrm{AR}$, is associated with sleep-disordered breathing, a condition that can have a profound effect on mental health, including increased psychiatric disorders [6]. The prevalence of AR is estimated to be between 9 and $16 \%$ in the US and up to $28.9 \%$ worldwide [7]. As AR represents a significant global health care problem, a thoughtful and rational approach to this disease is justified. Thus, multiple guidelines for the management of AR are now available and a stepwise approach is recommended by the ARIA/Ga2len collaboration [8].

Antihistamines are commonly used as first-line treatment for AR. They are particularly effective at relieving sneezing, itching, and watery rhinorrhea. First-generation antihistamines are no longer recommended because they show poor selectivity, and their use is limited because of their sedative, cardiovascular, and anticholinergic effects. Second-generation antihistamines have a higher potency and a longer duration of action compared with first-generation drugs, with no or minimal side effects. The rapid onset of action and the duration of activity of up to $24 \mathrm{~h}$ allow once-daily administration [9]. Several studies have shown that these new antihistamines have anti-inflammatory properties, conferring a therapeutic advantage in the management of the disease [10]. Many nonsedating antihistamines are clinically available and, in individual studies, they have shown their effectiveness in the treatment of AR symptoms. Despite the 
heterogeneous results seen across the class, the efficacy of these drugs against nasal congestion is still a matter of debate [11].

Fexofenadine hydrochloride is a potent, selective, nonsedating H1-receptor antagonist with proven efficacy in clinical symptom relief and in improving QoL in patients with AR and chronic idiopathic urticaria. This drug has also been shown to have a favorable effect on nasal congestion [12]. The results of head-to-head comparative trials suggest that fexofenadine might offer distinct advantages compared with some other antihistamines. Fexofenadine has been shown to be more effective than loratadine [13] at relieving the individual symptoms of nasal congestion and itchy, watery, red eyes, and it has been shown to have an efficacy comparable to that of cetirizine $[14,15]$ but with lesser side effects [16].

Fexofenadine is highly selective for peripheral H1 receptors and does not cross the blood-brain barrier [17]. In addition, fexofenadine does not interact with muscarinic receptors and is devoid of adverse cardiac effects [18]. Fexofenadine is also well tolerated in children aged 2-5 years with AR [19].

Evidence-based medicine is a concept of increasing relevance as it represents the faculty of making medical choices uniformly on the basis of a critical approach of a certain validity focused on the strength of demonstrative proof [20]. The current guidelines for AR are a collection of recommendations based on the principles of evidencebased medicine. According to the classical criteria, suggested by the method of Sheckelle et al. [21] for developing guidelines, conclusions from well-designed meta-analyses and randomized controlled clinical trials represent the strongest proof (level I) for establishing the efficacy of an intervention. A meta-analysis is a statistical technique which combines the results of independent single studies, providing a quantitative estimation of the global effect of an intervention by using particular solutions aimed at reducing the potential biases and the effects of heterogeneity between the sources.

In this review, we evaluated the efficacy of fexofenadine, compared to placebo, in reducing total and individual symptom scores in patients with AR by means of a systematic review and meta-analysis of the available randomized, double-blind and placebo-controlled clinical trials. A safety evaluation was performed as well. Since specific evidence needs to be provided to address recommendations in a pediatric population according to regulatory agencies, we attempted an estimation of the effect of benefits and disadvantages judging the quality of this evidence following the suggestions of the Allergic
Rhinitis and its Impact of Asthma-Grading of Recommendations Assessment, Development and Evaluation (ARIA-GRADE) Working Group [22]. A review protocol was not registered.

\section{Methods}

\section{Search Strategy}

We searched OVID, Medline, Embase, and the Web of Science up to December 31, 2007, for randomized, double-blind, placebocontrolled clinical trials evaluating the efficacy of fexofenadine for the treatment of AR. The Medline search strategy retrieved citations containing the exploded subject heading fexofenadine (histamine-H1-antagonists, antiallergic agents, rhinitis, allergic, seasonal, and H1-antagonist nonsedating) or text words Telfast ${ }^{\circledR}$ or Allegra ${ }^{\circledR}$, combined with exploded subject headings describing allergic disease (rhinitis, rhinoconjunctivitis, and hay fever), focused on the target population (humans). The search was conducted up to December 2007. We limited citations using a maximally sensitive strategy [23]. The same approach adapted to the specific databases was used for Embase and the Web of Science.

Two authors used independent search strategies. We screened the reference lists from all retrieved articles and from recent review articles to identify additional studies. The abstracts of relevant meetings were also searched. An English language restriction was adopted.

\section{Eligibility Criteria and Characteristics}

Only fully published, parallel-group, double-blind, placebocontrolled, randomized clinical trials (DBPC RCT) were included. The study population had to have a history of AR with or without allergic asthma and/or conjunctivitis and IgE sensitization proven by skin prick tests and/or specific IgE assays. All fexofenadine doses and treatment durations were considered. No restrictions in terms of disease duration were introduced. Postchallenge (or similar) studies were excluded from this analysis. Crossover designs not directly comparing fexofenadine and placebo were excluded.

The trial selection process was based on a first phase of title and abstract screening followed by a second phase of eligibility evaluation from the full text format. Both actions were performed by 2 investigators and checked by the principal investigator. The observed percentage agreement between the investigators for the assessment of inclusion was calculated using the $\kappa$ test $[23,24]$. Disagreements were resolved by discussion.

\section{Risk of Bias Assessment and Evaluation of Validity}

The risk of bias and methodological quality were assessed in duplicate using the Cochrane Collaboration tool [24]. We evaluated the following 6 parameters: (a) sequence generation, (b) allocation concealment, (c) blinding of caregivers, personnel and outcome assessors, (d) incomplete outcome data, (e) selective outcome reporting, and (f) other sources of bias. We graded each parameter of trial quality: (A) low risk of bias, (B) unclear risk of bias, and (C) high risk of bias, and we conducted an overall assessment for each controlled trial using the same 3 criteria [24]. Interrate agreement was calculated using the $\kappa$ statistic $[25,26]$. The quality of the evidence related to the estimation of benefits and 
Table 1. Features of the studies included in the meta-analysis

\begin{tabular}{|c|c|c|c|c|c|c|c|}
\hline & $\begin{array}{l}\text { study } \\
\text { design }\end{array}$ & $\begin{array}{l}\text { conceal- } \\
\text { ment of } \\
\text { allocation }\end{array}$ & blinding & $\begin{array}{l}\text { quality } \\
\text { score }^{1}\end{array}$ & $\begin{array}{l}\text { dropout } \\
\text { rate, \% }\end{array}$ & $\begin{array}{l}\text { overall quality } \\
\text { assessment } \\
\text { (risk of bias) }\end{array}$ & intervention \\
\hline Wahn et al. [46] & 2 arms & $\mathrm{B}$ & $\mathrm{B}$ & $3 / 5$ & 3.7 & medium & FEX 30 \\
\hline Bronsky et al. [47] & 4 arms & $\mathrm{B}$ & B & $3 / 5$ & 6 & medium & FEX 40/60/120 \\
\hline Bernstein et al. [49] & 4 arms & B & $\mathrm{B}$ & $3 / 5$ & 9 & medium & FEX 60/120/240 \\
\hline Howarth et al. [50] & 4 arms & B & $\mathrm{B}$ & $3 / 5$ & 14 & medium & FEX 120/180 \\
\hline Schapowal et al. [51] & 3 arms & B & B & $3 / 5$ & 8.2 & medium & FEX 180 \\
\hline Berger et al. [52] & 3 arms & A & A & $5 / 5$ & 3.4 & low & FEX 180 \\
\hline
\end{tabular}

All studies were DBRPC and parallel. FEX = Fexofenadine; $\mathrm{CZ}=$ cetirizine; $\mathrm{LO}=$ loratadine; $\mathrm{PL}=$ placebo; b.i.d. = two times daily; o.d. = once daily. ${ }^{1}$ Jadad score.

disadvantages in a pediatric population followed the suggestions of the GRADE Working Group by adopting the use of GradePro software 3.2.2

\section{Data Extraction}

Data collection was performed via a data extraction template form.

The outcomes measured were as follows: the primary outcome was the 12- or 24-hour reflective total symptom scores (TSS), the sum of sneezing, rhinorrhea, itchy nose/palate, and itchy/watery/ red eyes, excluding nasal congestion. The secondary outcomes were morning instantaneous TSS, reflective individual nasal symptom scores (rhinorrhea, sneezing, itching, and nasal obstruction), and the frequency of adverse events (AE). Variables such as peak inspiratory nasal flow, QoL, and inflammatory markers were assessed in some studies but were not included in this analysis because of the lack of sufficiently large patient populations. We conducted the analysis on an intention-to-treat population [24]. If more than 1 dose of fexofenadine was assessed, we selected the one considered more effective and safer by the authors of the paper. When data were not available in certain papers, the authors were contacted directly by e-mail. If the results were only presented in graphs, these were digitalized and then converted to numbers using the DigitizeIt 1.5.7 program (DigitizeIt 2003; Bormann, Braunschweig, Germany) [27]. Two independent reviewers (E.C. and M.P.) extracted data from the selected papers, reconciling differences by consensus.

\section{Data Synthesis and Heterogeneity Assessment}

We analyzed the posttreatment mean and standard deviation (SD) values for both the fexofenadine and placebo groups. In the selected papers, different scoring systems were used to evaluate symptoms; consequently, we analyzed them with the standardized mean differences (SMD) $[24,28,29]$. Dichotomous outcomes were analyzed with odds ratios (adverse effects frequency) [24, 28, 30, 31].
Heterogeneity was assessed using Cochran's Q statistic test and the $\mathrm{I}^{2}$ test. When a nonsubstantial heterogeneity among the outcomes was found $\left(\mathrm{I}^{2}<50 \%\right)$, a fixed-effects model (FEM) was used. An FEM uses the inverse variance approach and it is assumed that all studies come from a common population [24, 29]; for $\mathrm{I}^{2}<50 \%$, a random-effects model (REM) was used. All results are reported with $95 \%$ confidence intervals $(95 \% \mathrm{CI})$ and all $\mathrm{p}$ values are 2 -tailed. Details about the statistical methods used in this review were published previously [32]. The analysis was performed using the RevMan 5 program (The Cochrane Collaboration, Oxford, UK) [33].

Sensitivity Analysis and the Risk of Bias across Studies

A sensitivity analysis was planned to compare subsets of data in terms of different treatment durations, fexofenadine dosages, and data synthesis using both an FEM and an REM [24]. A funnel plot analysis was planned to estimate the likelihood of bias in the meta-analysis.

\section{Results}

\section{Search Results}

The primary search identified 2,152 records; 2,024 were excluded after screening because they were duplicates or not related to the topic, and 128 full-text articles were assessed for eligibility. Of these, 108 were excluded because they were reviews or pooled analyses, studies aimed at other purposes, had outcomes not valid for this review, were not placebo-controlled studies, had safety evaluations, were open or single-blind studies, or not randomized studies. Twenty clinical trials on fexofenadine in the treatment of AR were potentially relevant (fig. 1). Twelve comparative trials did not satisfy the inclusion 


\begin{tabular}{|c|c|c|c|c|c|c|}
\hline \multicolumn{4}{|l|}{ Study features } & \multicolumn{3}{|l|}{ Subjects } \\
\hline PL & $30 \mathrm{mg} / \mathrm{b}$. i.d. & 15 & $935(464 / 471)$ & children & $8.8 \pm 1.6(5-12)$ & SAR \\
\hline PL & 120 mg/b.i.d. & 14 & $589(137 / 138)$ & children and adults & $34 \pm 10(12-65)$ & SAR \\
\hline $\mathrm{PL}$ & $120 \mathrm{mg} /$ b.i.d. & 14 & $575(144 / 141)$ & children and adults & $32 \pm 10(12-65)$ & SAR \\
\hline PL, CZ 10 mg & 180 mg/o.d. & 14 & $842(202 / 201)$ & children and adults & $33(13-66)$ & SAR \\
\hline PL, Butterbur Ze339 & 180 mg/o.d. & 14 & $330(113 / 107)$ & adults & $38.6 \pm 14(18-80)$ & SAR \\
\hline PL, desloratadine $5 \mathrm{mg}$ & 180 mg/o.d. & 15 & $722(288 / 244)$ & children and adults & $34.5 \pm 14.09(12-84)$ & SAR \\
\hline
\end{tabular}

Fig. 1. Search strategy and retrieved ar-

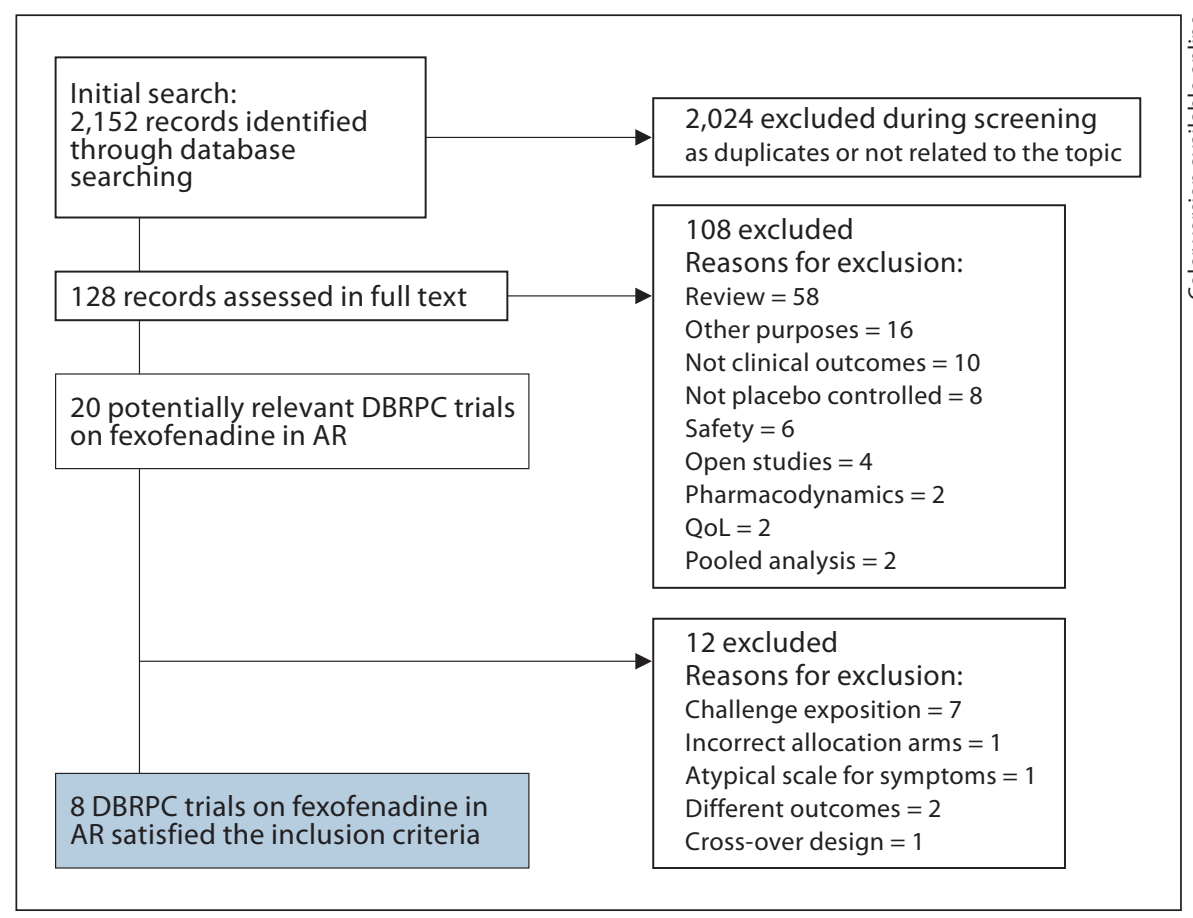

criteria [34-45]. Eight DBPC RCT satisfied the inclusion criteria, but data from 2 were not reported and could not be extracted from the manuscript; the attempt to obtain data directly from the authors failed as well, so graphics were digitized and the SD estimated using an imputation method. Finally, 8 trials were included in the meta-analysis. The $\kappa$ statistic for interrate agreement in terms of study eligibility was 0.85 .

Systematic Review on the Efficacy of Fexofenadine in SAR
Trial Characteristics

Table 1 outlines the characteristics of the studies and subjects included in the meta-analysis. Eight DBPC RCT including a total of 3,532 participants were assessed for the primary outcome and were included in this review $[13,46-52]$. All of the retrieved studies were performed to assess the efficacy and safety of fexofenadine in participants with seasonal AR (SAR). The participants' range of

Int Arch Allergy Immunol 2011;156:1-15 


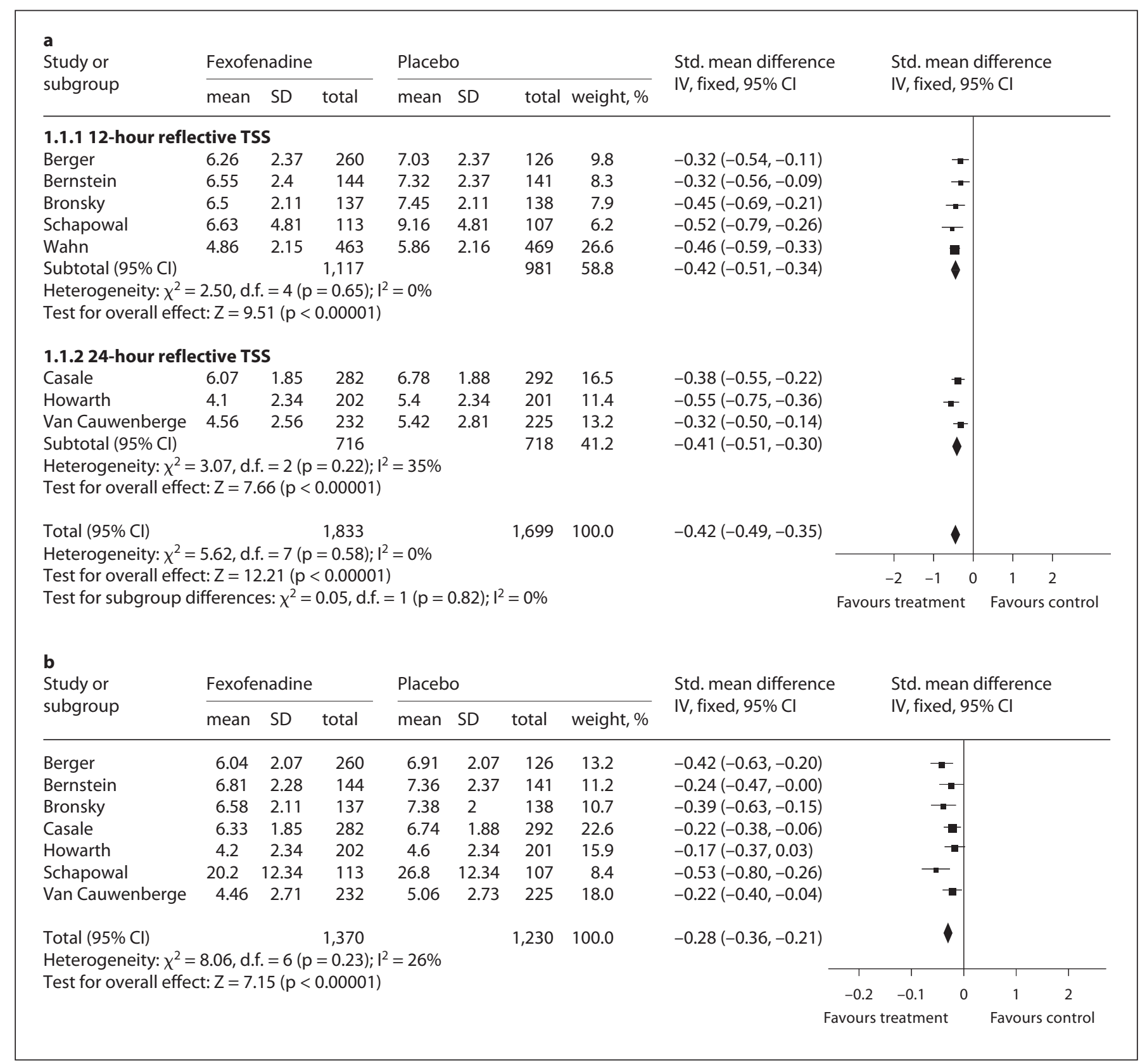

Fig. 2. Efficacy of fexofenadine in patients with AR compared to placebo (outcomes: a reflective TSS and b morning instantaneous TSS).

age was 5-84 years. All but 1 study explored a mixed adult-pediatric population. The study by Wahn et al. [46] included only children [5-12]. Each trial included a median of 705 participants (range 330-935). All studies provided the study medication in the form of tablets. The median duration of treatment was 14 days. Reflective TSS were available in 8 studies $(\mathrm{n}=3,532) ; 7$ trials assessed instantaneous TSS $(\mathrm{n}=2,600)$. Data on the individual nasal symptom scores were available in 7 studies $(\mathrm{n}=$ $3,307)$.

\section{Methodological Quality of the Included Studies}

All of the included trials were randomized, parallel group, double blind, and placebo controlled. All investi- 
Table 2. Reported AE in the active and placebo treatment patients included in the safety evaluation

\begin{tabular}{|c|c|c|}
\hline \multirow[t]{2}{*}{ Reference } & \multicolumn{2}{|c|}{ Number of patients reporting AE (active/placebo) } \\
\hline & total patients & most commonly reported specific $\mathrm{AE}$ \\
\hline Wahn et al. [46] & $85 / 88$ & $\begin{array}{l}\text { Headache }(23 / 13) \text {, epistaxis }(7 / 5) \text {, upper respiratory infection }(11 / 5) \text {, pharyngitis }(6 / 1) \text {, } \\
\text { sinusitis }(6 / 0) \text {, nausea }(5 / 1) \text {, rash }(5 / 3) \text {, accidental injury }(4 / 6) \text {, asthma }(3 / 9) \text {, infection }(1 / 5) \text {, } \\
\text { gastrointestinal pain }(1 / 5) \text {, and leukopenia }(1 / 0)\end{array}$ \\
\hline Bronsky et al. [47] & $18 / 18$ & Headache $(3 / 4)$ \\
\hline Casale et al. [48] & $86 / 88$ & Upper respiratory infection (9/9), pharyngitis (6/9), and back pain $(8 / 4)$ \\
\hline $\begin{array}{l}\text { Van Cauwenberge } \\
\text { et al. [13] }\end{array}$ & $39 / 33$ & Headache $(7 / 5)$, sedation $(4 / 3)$, asthenia $(1 / 1)$, pharyngitis $(3 / 1)$, diarrhea $(4 / 0)$, and nausea $(1 / 3)$ \\
\hline Bernstein et al. [49] & $10 / 13$ & Headache $(6 / 4)$, pharyngitis $(1 / 2)$, dry mouth $(0 / 2)$, cough $(0 / 2)$, and leukopenia $(1 / 1)$ \\
\hline Howarth et al. [50] & $50 / 53$ & Headache (8/15), asthenia (3/2), and drowsiness (14/7) \\
\hline Schapowal et al. [51] & $8 / 7$ & Headache $(0 / 1)$, sedation $(6 / 3)$, upper respiratory infection $(1 / 2)$, sinusitis $(1 / 2)$, and nausea $(1 / 2)$ \\
\hline Berger et al. [52] & $52 / 19$ & Headache $(11 / 2)$, sedation $(3 / 0)$, nausea $(3 / 0)$, and upper respiratory infection $(3 / 1)$ \\
\hline
\end{tabular}

gators asked patients to provide their informed consent before enrolment. All trials reported dropouts and withdrawals and analyzed patients who completed the trial; the dropout rate ranged from 1.2 to $14 \%$. The overall assessment for the risk of bias, obtained from the analysis of allocation concealment, attrition, and detection bias, resulted in a medium level (table 1). The score for interrate agreement on methodological quality scores was 0.80 .

\section{Data Synthesis}

Eight trials assessed the daily reflective TSS (fig. 2a). The 12-hour reflective TSS was evaluated in 5 studies [46, $47,49,51,52]$ and the 24-hour reflective TSS in $3[13,48$, 50]. Out of the 3,532 participants 1,833 received fexofenadine and 1,699 placebo. Fexofenadine-treated participants showed a significant reduction of TSS compared with those treated with placebo (SMD -0.42; 95\% CI -0.49 to $-0.35, \mathrm{p}<0.00001)$. No substantial heterogeneity was found $\left(\chi^{2}=5.62 ; \mathrm{p}=0.58, \mathrm{I}^{2}=0 \%\right)$. No significant differences were observed when both the 12- and 24-hour reflective TSS were compared (fig. 3).

Morning instantaneous TSS were available in 6 studies (1,370 participants treated with fexofenadine and 1,230 with placebo). A significant reduction in these symptoms was found in subjects receiving fexofenadine (SMD -0.28; $95 \% \mathrm{CI}-0.36$ to $-0.21, \mathrm{p}<0.00001)$. No substantial heterogeneity was found $\left(\chi^{2}=8.06 ; \mathrm{p}=0.23, \mathrm{I}^{2}=0.26 \%\right.$ ) (fig. $2 \mathrm{~b}$ ).

Data for individual nasal symptom scores were available in 7 studies (1,720 participants treated with fexofen-

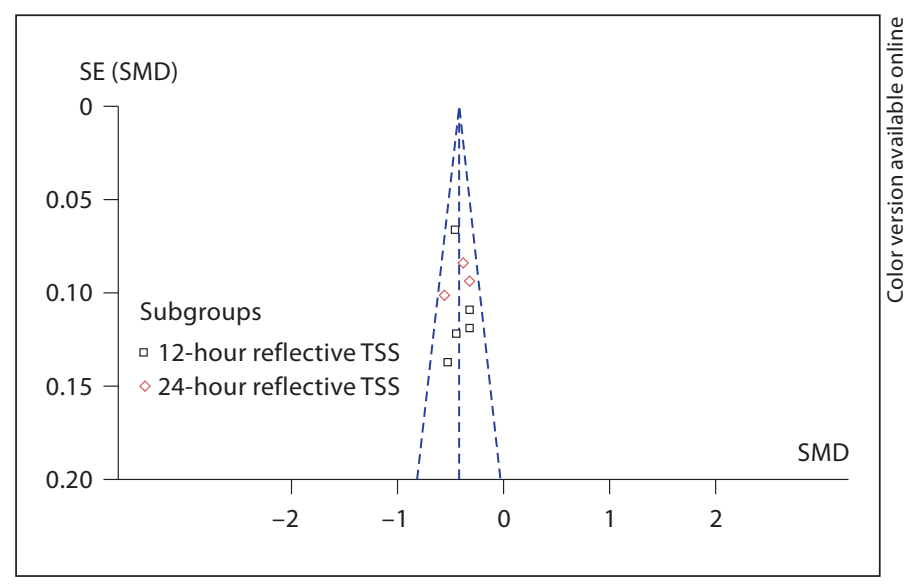

Fig. 3. Funnel plot for reflective TSS (comments in text).

adine and 1,587 with placebo). A significant reduction in the SMD for nasal stuffiness/congestion (SMD -0.17; 95\% CI -0.24 to $-0.10, \mathrm{p}<0.00001$ ), rhinorrhea (SMD -0.24 ; $95 \% \mathrm{CI}-0.31$ to $-0.17, \mathrm{p}<0.00001$ ), sneezing (SMD -0.37 ; $95 \% \mathrm{CI}-0.44$ to $-0.30, \mathrm{p}<0.00001)$, and nasal itching (SMD $-0.31 ; 95 \%$ CI -0.38 to $-0.24, \mathrm{p}<0.00001$ ) was found in subjects who received fexofenadine. The heterogeneity was $0,22,15$, and $5 \%$, respectively (fig. 4).

\section{Safety}

With regard to AE, 8 trials reported the frequency of adverse reactions (patients: 1,874 fexofenadine/1,729 pla- 


\begin{tabular}{|c|c|c|c|c|c|c|c|c|c|c|}
\hline \multirow{2}{*}{$\begin{array}{l}\text { Study or } \\
\text { subgroup }\end{array}$} & \multicolumn{3}{|c|}{ Fexofenadine } & \multicolumn{4}{|c|}{ Placebo } & \multirow{2}{*}{$\begin{array}{l}\text { Std. mean difference } \\
\text { IV, fixed, } 95 \% \mathrm{Cl}\end{array}$} & \multirow{2}{*}{\multicolumn{2}{|c|}{$\begin{array}{l}\text { Std. mean difference } \\
\text { IV, fixed, } 95 \% \mathrm{Cl}\end{array}$}} \\
\hline & mean & SD & total & mean & SD & total & weight, $\%$ & & & \\
\hline \multicolumn{11}{|l|}{ 1.3.1 Sneezing } \\
\hline Bronsky & 1.49 & 0.58 & 137 & 1.76 & 0.58 & 138 & 2.1 & $-0.46(-0.70,-0.22)$ & & \\
\hline Casale & 1.34 & 0.5 & 282 & 1.57 & 0.51 & 292 & 4.3 & $-0.45(-0.62,-0.29)$ & 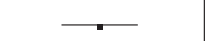 & \\
\hline Wahn & 1.2 & 0.67 & 463 & 1.48 & 0.67 & 464 & 7.0 & $-0.42(-0.55,-0.29)$ & 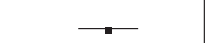 & \\
\hline Van Cauwenberge & 1.14 & 0.75 & 232 & 1.45 & 0.78 & 225 & 3.5 & $-0.40(-0.59,-0.22)$ & 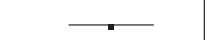 & \\
\hline Bernstein & 1.5 & 0.72 & 144 & 1.66 & 0.71 & 141 & 2.2 & $-0.22(-0.46,0.01)$ & & \\
\hline Howarth & 1 & 1.42 & 202 & 1.3 & 1.42 & 201 & 3.1 & $-0.21(-0.41,-0.02)$ & & \\
\hline Berger & -0.49 & 0.58 & 260 & -0.33 & 0.58 & 126 & 2.6 & $-0.28(-0.49,-0.06)$ & & \\
\hline Subtotal $(95 \% \mathrm{Cl})$ & & & 1,720 & & & 1,587 & 24.8 & $-0.37(-0.44,-0.30)$ & & \\
\hline \multicolumn{11}{|c|}{$\begin{array}{l}\text { Heterogeneity: } \chi^{2}=7.06, \text { d.f. }=6(p=0.32) ; I^{2}=15 \% \\
\text { Test for overall effect: } Z=10.42(p<0.00001)\end{array}$} \\
\hline \multicolumn{11}{|l|}{ 1.3.2 Rhinorrhea } \\
\hline Bernstein & 1.94 & 0.72 & 144 & 1.97 & 0.71 & 141 & 2.2 & $-0.04(-0.27,0.19)$ & & \\
\hline Bronsky & 1.98 & 0.58 & 137 & 2.06 & 0.58 & 138 & 2.1 & $-0.14(-0.37,0.10)$ & & \\
\hline Casale & 1.73 & 0.5 & 282 & 1.88 & 0.51 & 292 & 4.4 & $-0.30(-0.46,-0.13)$ & . & \\
\hline Howarth & 1.2 & 0.14 & 202 & 1.4 & 1.42 & 201 & 3.1 & $-0.20(-0.39,-0.00)$ & & \\
\hline Van Cauwenberge & 1.28 & 0.78 & 232 & 1.57 & 0.78 & 225 & 3.5 & $-0.37(-0.56,-0.19)$ &. & \\
\hline Wahn & 1.4 & 0.69 & 463 & 1.6 & 0.69 & 464 & 7.1 & $-0.29(-0.42,-0.16)$ & 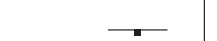 & \\
\hline Berger & -0.61 & 0.38 & 260 & -0.56 & 0.38 & 126 & 2.6 & $-0.13(-0.34,0.08)$ & & \\
\hline Subtotal $(95 \% \mathrm{Cl})$ & & & 1,720 & & & 1,587 & 25.1 & $-0.24(-0.31,-0.17)$ & 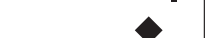 & \\
\hline \multicolumn{11}{|c|}{ Heterogeneity: $\chi^{2}=7.64$, d.f. $=6(p=0.27) ; 1^{2}=22 \%$} \\
\hline \multicolumn{11}{|c|}{ Test for overall effect: $Z=6.81(p<0.00001)$} \\
\hline \multicolumn{11}{|c|}{ 1.3.3 Nasal congestion } \\
\hline Bernstein & 2.09 & 0.6 & 144 & 2.16 & 0.59 & 141 & 2.2 & $-0.12(-0.35,0.12)$ & & \\
\hline Bronsky & 2.08 & 0.58 & 137 & 2.17 & 0.58 & 138 & 2.1 & $-0.15(-0.39,0.08)$ & & \\
\hline Casale & 1.96 & 0.5 & 282 & 2.04 & 0.51 & 292 & 4.4 & $-0.16(-0.32,0.01)$ & & \\
\hline Howarth & 1.4 & 1.42 & 202 & 1.5 & 1.42 & 201 & 3.1 & $-0.07(-0.27,0.13)$ & - & \\
\hline Van Cauwenberge & 1.44 & 0.74 & 232 & 1.66 & 0.68 & 225 & 3.5 & $-0.31(-0.49,-0.12)$ &. & \\
\hline Wahn & 1.6 & 0.64 & 463 & 1.71 & 0.63 & 464 & 7.2 & $-0.17(-0.30,-0.04)$ & 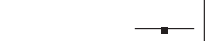 & \\
\hline Berger & -0.48 & 0.44 & 260 & -0.4 & 0.44 & 126 & 2.6 & $-0.18(-0.39,0.03)$ & & \\
\hline Subtotal $(95 \% \mathrm{Cl})$ & & & 1,720 & & & 1,587 & 25.2 & $-0.17(-0.24,-0.10)$ & & \\
\hline \multicolumn{11}{|c|}{ Heterogeneity: $\chi^{2}=3.42$, d.f. $=6(p=0.75) ;\left.\right|^{2}=0 \%$} \\
\hline \multicolumn{11}{|c|}{ Test for overall effect: $Z=4.87(p<0.00001)$} \\
\hline \multicolumn{11}{|l|}{ 1.3.4 Nasal itching } \\
\hline Bernstein & 1.59 & 0.72 & 144 & 1.76 & 0.71 & 141 & 2.2 & $-0.24(-0.47,-0.00)$ & & \\
\hline Bronsky & 1.69 & 0.7 & 137 & 1.82 & 0.7 & 138 & 2.1 & $-0.19(-0.42,0.05)$ & & \\
\hline Casale & 1.51 & 0.5 & 282 & 1.69 & 0.51 & 292 & 4.4 & $-0.36(-0.52,-0.19)$ &. & \\
\hline Howarth & 1 & 0.14 & 202 & 1.4 & 1.42 & 201 & 3.1 & $-0.40(-0.59,-0.20)$ &. & \\
\hline Van Cauwenberge & 1.18 & 0.61 & 232 & 1.3 & 0.75 & 225 & 3.5 & $-0.18(-0.36,0.01)$ & & \\
\hline Wahn & 1.17 & 0.67 & 463 & 1.43 & 0.67 & 464 & 7.1 & $-0.39(-0.52,-0.26)$ & 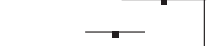 & \\
\hline Berger & -0.67 & 0.63 & 260 & -0.52 & 0.63 & 126 & 2.6 & $-0.24(-0.45,-0.02)$ & $\longrightarrow$ & \\
\hline \multirow{2}{*}{\multicolumn{11}{|c|}{$\begin{array}{l}\text { Heterogeneity: } \chi^{2}=6.34, \text { d.f. }=6(p=0.39) ; I^{2}=5 \% \\
\text { Test for overall effect: } Z=8.71(p<0.00001)\end{array}$}} \\
\hline & & & & & & & & & & \\
\hline Total $(95 \% \mathrm{Cl})$ & & & 6,880 & & & 6,348 & 100.0 & $-0.27(-0.31,-0.24)$ & $\downarrow$ & \\
\hline \multicolumn{6}{|c|}{ Heterogeneity: $x^{2}=41.98$, d.f. $=27(p=0.03) ; 1^{2}=36 \%$} & & & & $T_{1}$ & 1 \\
\hline \multicolumn{9}{|c|}{ Test for overall effect: $Z=15.39(p<0.00001)$} & $-0.5-0.250$ & 0.250 .5 \\
\hline \multicolumn{9}{|c|}{ Test for subgroup differences: $\chi^{2}=17.51$, d.f. $=3(p=0.0006), I^{2}=82.9 \%$} & Favours treatment & Favours control \\
\hline
\end{tabular}

Fig. 4. Efficacy of fexofenadine in patients with AR compared to placebo (outcome: daily reflective individual nasal symptom scores). 


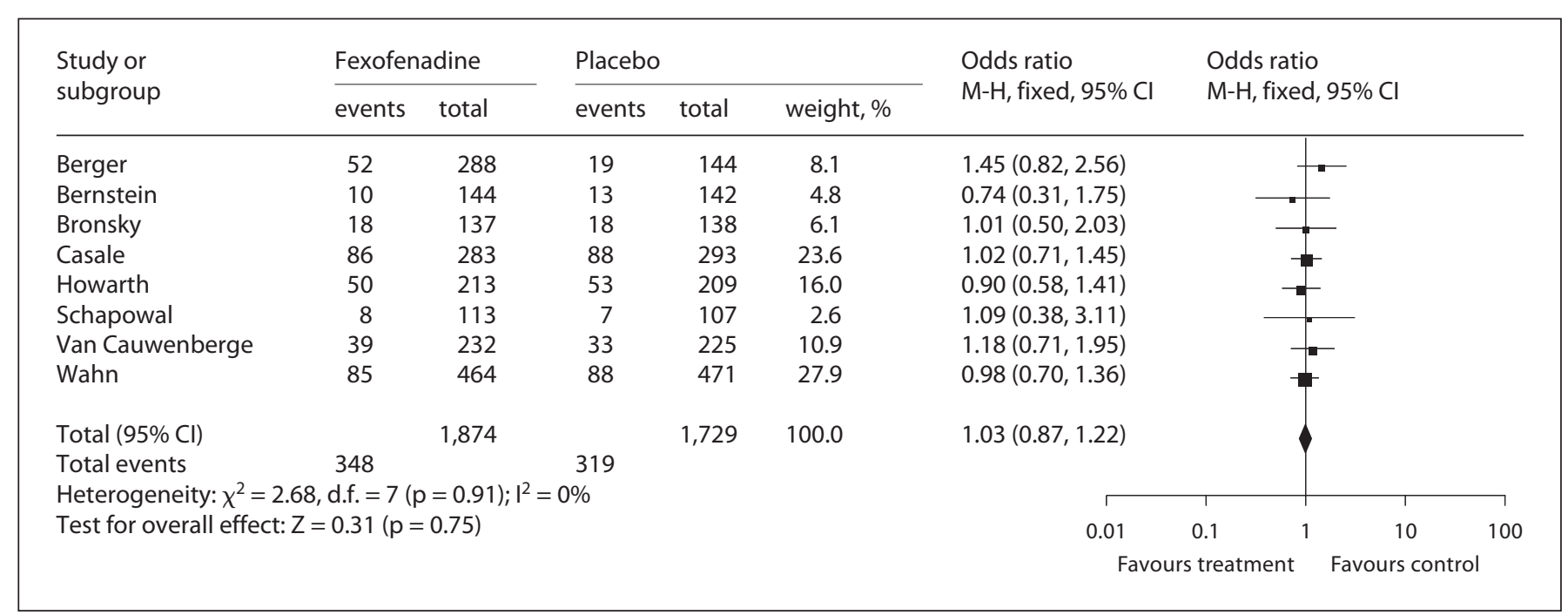

Fig. 5. Frequency of reported AE in subjects treated with fexofenadine compared to placebo (outcome: AE frequency).

cebo). The frequency of AE was similar in both groups $(\mathrm{OR}=1.03$; $95 \% \mathrm{CI} 0.87-1.22, \mathrm{p}=0.75)$. There was no heterogeneity across the studies $\left(\chi^{2}=2.68 ; \mathrm{p}=0.91 \%\right.$, $\mathrm{I}^{2}=0 \%$ ) (fig. 5). The relative incidence of reported AE, related or not related to drug consumption, is shown in table 2.

\section{Assessment of Benefits and Disadvantages in a \\ Pediatric Subpopulation}

The evidence of the benefits and disadvantages of using fexofenadine in children affected by SAR can be extrapolated by the only study including exclusively kids by Wahn et al. [46] and by the indirect evidence of studies including a mixed population of adults and kids. Regarding the first assumption, the estimations are based on a large sample size (464/471) where a relatively large effect for benefits and a low risk for disadvantages were demonstrated at least for 12-hour reflective TSS, sneezing, and the AE rate. The quality of this evidence suggests a moderate confidence. For other outcomes, this confidence is low due to the modest effects achieved together with the indirectness of the information from studies with a mixed population (see table 3 for details).

\section{Sensitivity Analysis}

Post hoc sensitivity analyses using a REM did not substantially change the overall significance for reflective TSS (SMD $-0.42 ; 95 \% \mathrm{CI}-0.49$ to $-0.35, \mathrm{p}<0.00001$ ) or instantaneous TSS (SMD -0.29 ; 95\% CI -0.38 to -0.20 , $\mathrm{p}<0.00001)$. Similar results were obtained for individual symptoms using REM: sneezing (SMD -0.36; 95\% CI -0.44 to $-0.29, \mathrm{p}<0.00001$ ), rhinorrhea (SMD -0.23 ; $95 \%$ CI -0.31 to $-0.15, \mathrm{p}<0.00001$ ), nasal congestion (SMD $-0.17 ; 95 \% \mathrm{CI}-0.24$ to $-0.10, \mathrm{p}<0.00001$ ), and nasal itching (SMD $-0.31 ; 95 \% \mathrm{CI}-0.38$ to $-0.23, \mathrm{p}<0.00001$ ). No comparisons of treatment duration were performed due to the limited number of studies included in the analysis. Because of the very low interstudy heterogeneity, no analysis could be performed by excluding outlying trial or subgroup analysis. The exclusion of studies whose data were estimated by an imputation method did not significantly change the results of the analysis. Despite the fact that the funnel plots apparently did not show substantial asymmetry, the impact of a possible publication bias cannot be excluded because, with a low number of studies included, the reliability of this kind of assessment is weak (fig. 3) [53]. On the other hand, the observation of a gap in the 2 bottom corners of the graphs, for all of the explored outcomes, may indicate unpublished small studies (fig. 6). The measured overall estimates of effect were not substantially driven by small studies' effects. No studies had markedly different intervention effect estimates (outliers) or were individually highly influential in the meta-analysis; this indicates the absence of fragility in the results. 


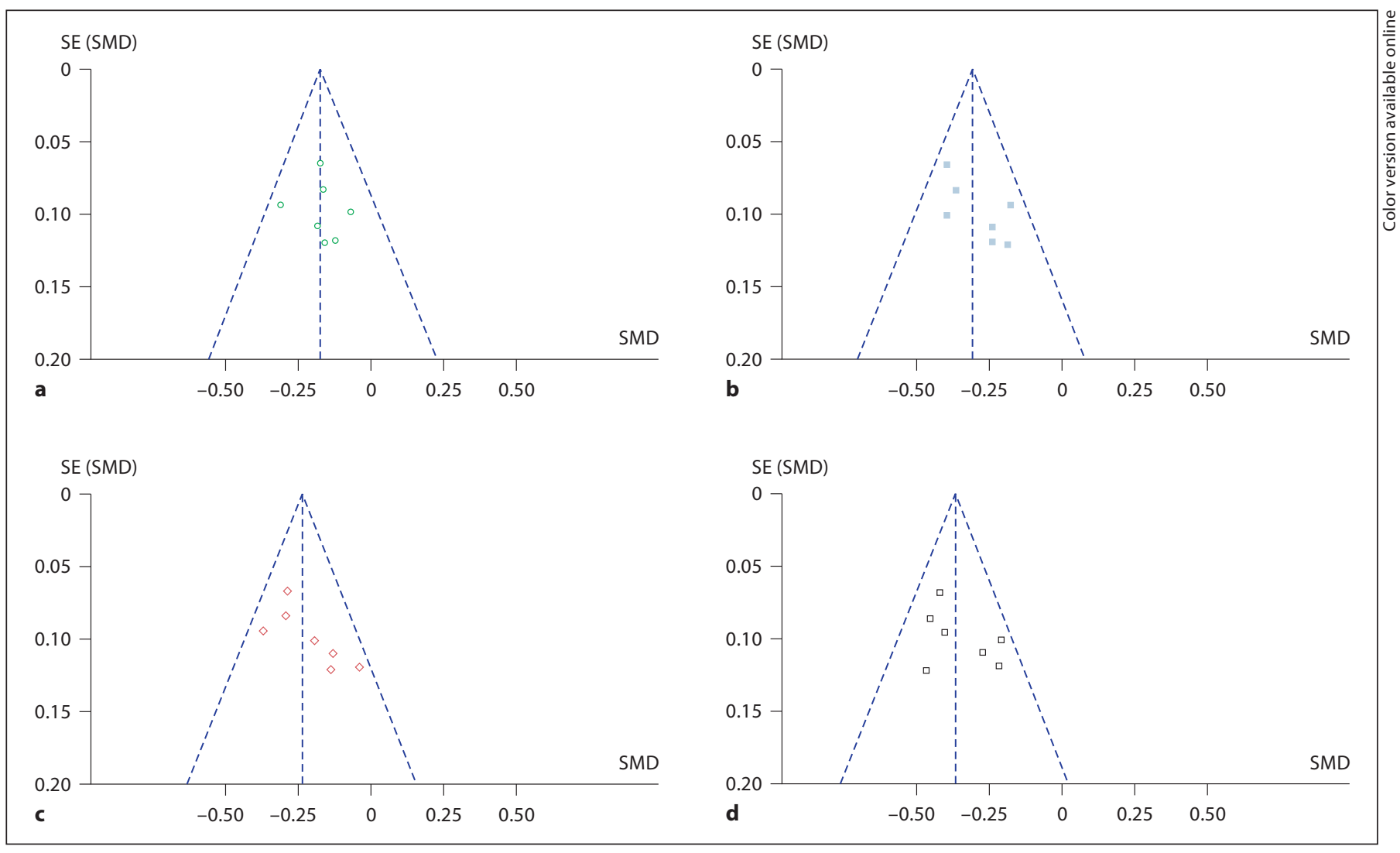

Fig. 6. Funnel plots for individual symptom scores (comments in the text). a Nasal congestion. b Nasal itching. c Rhinorrea. d Sneezing.

\section{Discussion}

For a number of reasons, the emphasis on evidencebased medicine has become very important in recent years. The amount and complexity of biomedical information have increased exponentially. On the other hand, the task of transposing research findings to clinical practice has become more and more difficult. The availability of valid, robust tools which can recognize clearly effective interventions worth applying is a real need. This reality goes hand in hand with the global reduction of economic resources and the increase in health care demand, which forces policy makers to ask for recommendations based on high-quality proof of evidence $[54,55]$. In this context, guidelines find their role. Guidelines are not a fixed model of reference for clinical practice but rather express the need for an approach where clinical decisions are the result of the integration of medical experience and the conscientious, explicit, and judicious use of the best scientific evidence, without ignoring the patient's viewpoint.
This is the real meaning of evidence-based medicine [56]. In the last 8 years, the GRADE Working Group, born as an informal collaboration of experts with an interest in addressing the shortcomings of the current grading systems in health care, has worked to develop a common, sensible, and transparent approach to grading the quality of evidence and the strength of recommendations [57]. According to this model, systematic reviews of the effects of health care provide essential, but not sufficient, information for making well-informed recommendations. There are a number of factors that one needs to consider when grading recommendations. One issue is the degree of confidence in the best estimates of the risk/benefit ratio. The methodological quality of the evidence captures this degree of confidence. There are a number of factors that may influence the strength of a recommendation, such as study design, the consistency of results, the directness of evidence, and the likelihood of bias, because the quality of the evidence is directly related to the quality of the study [58]. 
Table 3. GRADE profile for the quality of evidence related to the assessment in a pediatric population. Should fexofenadine be used for SAR in children?

\begin{tabular}{|c|c|c|c|c|c|}
\hline \multicolumn{3}{|l|}{ Quality assessment } & \multicolumn{2}{|l|}{ Summary of findings } & \multirow{3}{*}{$\begin{array}{l}\text { Impor } \\
\text { tance }\end{array}$} \\
\hline \multirow{2}{*}{$\begin{array}{l}\text { number design } \\
\text { of studies/ } \\
\text { Ref. No. }\end{array}$} & \multirow[t]{2}{*}{ limitations inconsistency } & \multirow{2}{*}{$\begin{array}{l}\text { other con- } \\
\text { siderations }\end{array}$} & number of patients & quality & \\
\hline & & & $\begin{array}{l}\text { fexofen- control } \\
\text { adine }\end{array}$ & $\begin{array}{l}\text { relative absolute } \\
(95 \% \mathrm{CI})\end{array}$ & \\
\hline
\end{tabular}

12-hour reflective TSS (range of scores 0-0; better is indicated by less)

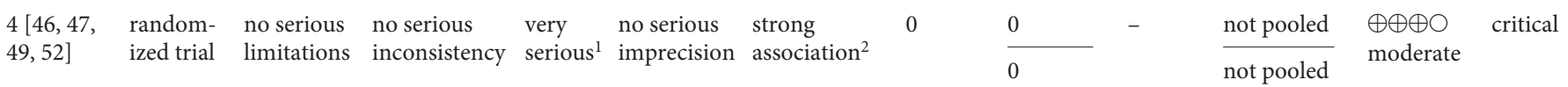

24-hour reflective TSS (range of scores: $0-0$; better is indicated by less)

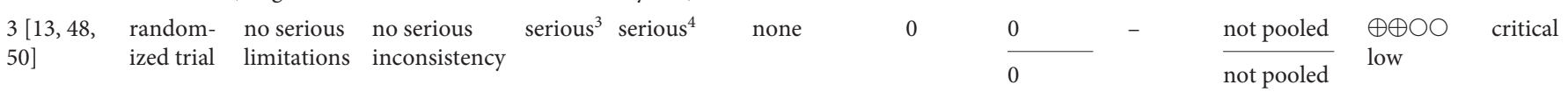

Morning instantaneous symptoms scores (range of scores $0-0$; better is indicated by less)

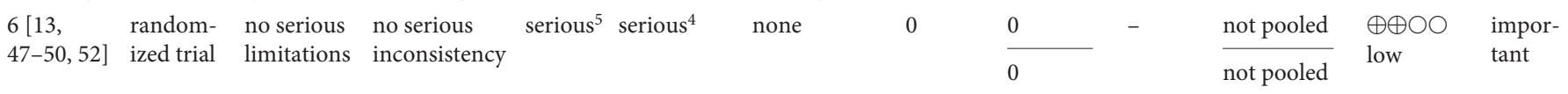

Sneezing (range of scores $0-0$; better is indicated by less)

46-50,52] ized trial limitations inconsistency serious ${ }^{1}$ imprecision association ${ }^{6} \quad \frac{0}{0} \quad \frac{-}{\text { not pooled }_{\text {moderate }}} \quad \frac{\text { tant }}{0}$

Rhinorrhea (range of scores $0-0$; better is indicated by less)

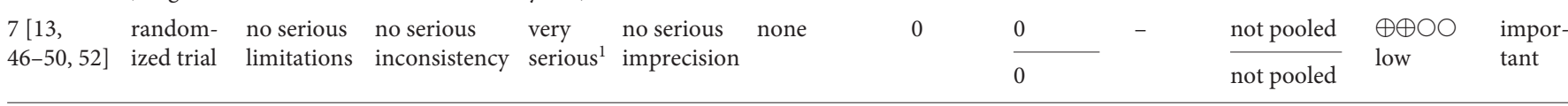

Nasal congestion (range of scores $0-0$; better is indicated by less)

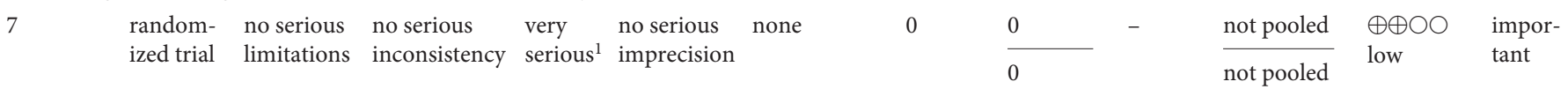

Nasal itching (range of scores 0-0; better is indicated by less)

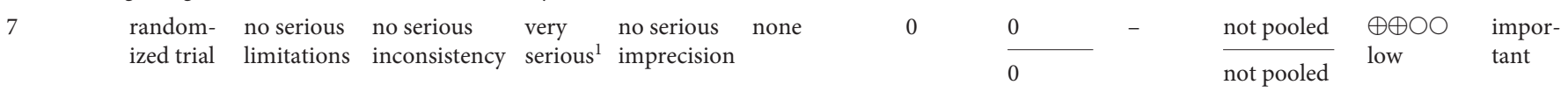

AE rate

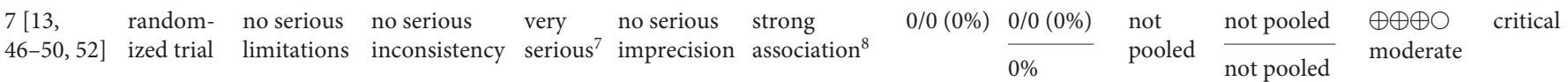

${ }^{1}$ Only 2 trials (Berger et al. [46] and Wahn et al. [52]) reported the number of kids included in the analysis and no separate results were given for the first. The significant effect size of the studies including a mixed population may address the indirect evidence of the efficacy of fexofenadine in children.

${ }^{2}$ In the study by Wahn et al. [46] on a population of 464 children in the active arm and 471 in the placebo arm, the OR of effect is calculated as 2.29.

${ }^{3}$ No explanation was provided.

${ }^{4}$ Since the number of kids included is not known, we assume that the number of events is lower than 300 .

${ }^{5}$ None of the studies reported separate results or the number of children in the analysis. The significant effect size of the studies including a mixed population may address indirect evidence of efficacy of fexofenadine in children.

${ }^{6}$ In the study by Wahn et al. [46] on a population of 464 children in the active arm and 471 in the placebo arm, the OR of effect is calculated as 2.14.

${ }^{7}$ Only 2 trials reported the number of kids included in the analysis (Berger et al. [46] and Wahn et al. [52]) and no separate results were given for the first. The relative risk estimated in the studies including a mixed population may address the indirect evidence of the safety of fexofenadine in children.

${ }^{8}$ The OR very close to 1 found in the study by Wahn et al. [46], on a relatively large population, may suggest a very low probability of difference of risk for $\mathrm{AE}$ between active and placebo. 


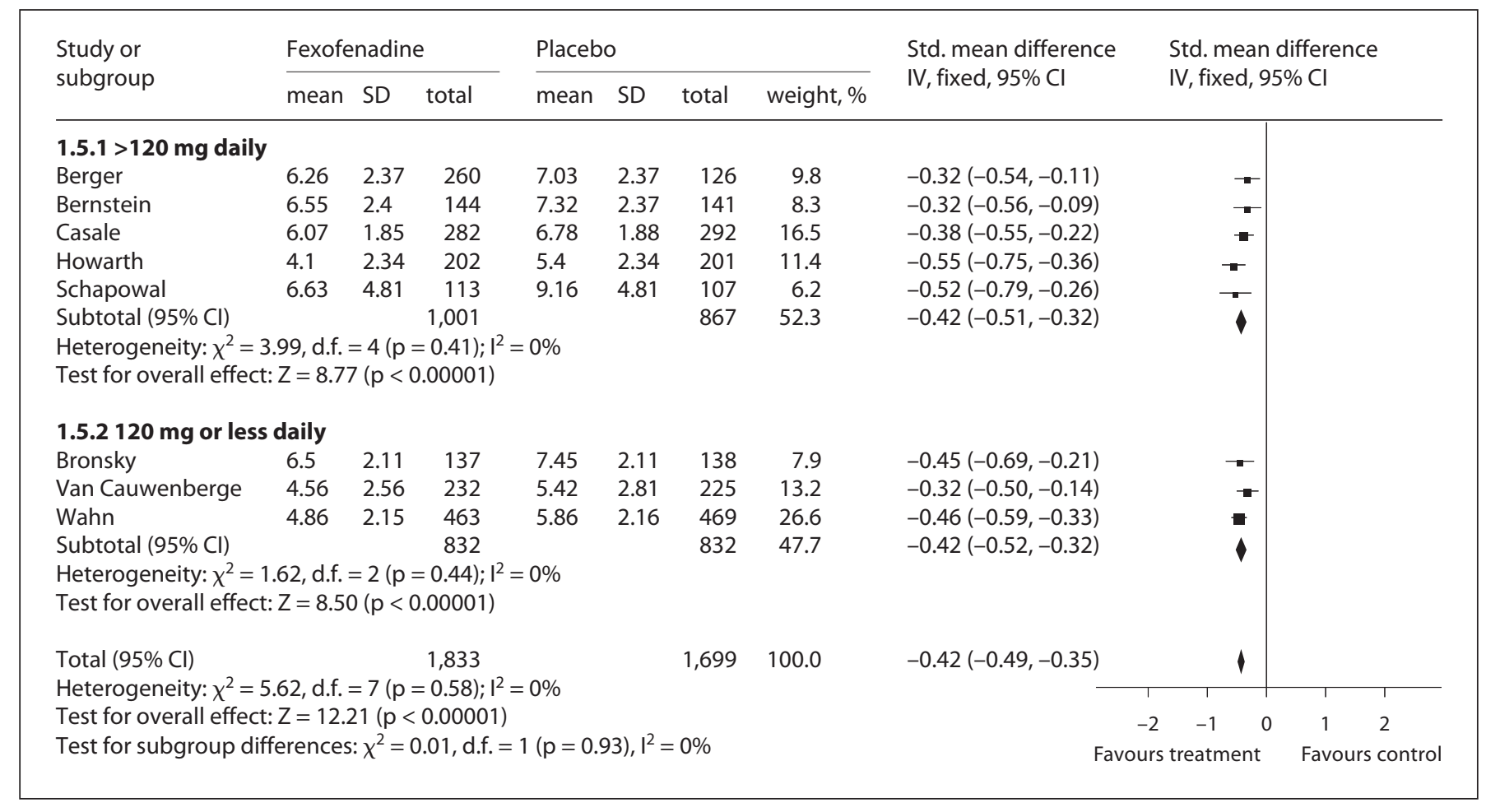

Fig. 7. Comparison between studies administering $120 \mathrm{mg}$ (or less) and more than $120 \mathrm{mg}$ daily of fexofenadine (outcome: reflective TSS).

This meta-analysis assessed the efficacy of fexofenadine in the treatment of SAR, identifying a total of 8 randomized, controlled trials that met the inclusion criteria. We confirm that the effects of this drug, previously seen in individual studies, are supported by this systematic review.

Fexofenadine showed an overall beneficial effect on the symptoms of SAR as measured by TSS and individual nasal symptom scores. The consistency of these findings reinforces the strength of the global evidence of clinical efficacy although the size effect we calculated can be considered moderate according to the common Cohen's scale [59].

In this meta-analysis, studies using different doses of fexofenadine were included. We selected patient samples receiving the highest dose currently available commercially in a single tablet (120 or $180 \mathrm{mg}$ ), but a post hoc analysis did not detect any differences in terms of the effect on TSS with respect to placebo when comparing studies administering $120 \mathrm{mg}$ (or less) and more than 120 mg daily (fig. 7).

We compared studies with a medium Jadad score (3/5) and with a medium risk of bias in the overall assessment, with no relevant differences in the intensity of the interventions or differences in the underlying risk between studies of different sizes. The absence of a description of the concealment of allocation and blinding procedures together with the power calculation represents the major deficiencies of the included RCTs. Moreover, in 2 trials data were extracted by graph digitalization and imputation.

Attrition bias is an important aspect able to create uncertainty in interpreting study results, but in this systematic review we found a dropout rate ranging from 1.2 to $14 \%$. Since we introduced language and electronic database restrictions, it is possible that not all of the relevant studies have been included, thus making the small number of included trials a weak point. Nevertheless, Higgins et al. [60] showed that the number of existing Cochrane meta-analyses with more than 10 studies is currently low. On the other hand, the global population explored in this review is high (3,143 patients) and the individual size of the trials is high on average (in the smallest study, 204 patients completed the study). With these conditions, therefore, the risk that small studies with an extreme outcome influenced the overall results is very low. 
The only satisfactory way to address publication bias and the inadequacy of individual trials in a meta-analysis is through the prospective registration of all of the clinical trials and through adherence to validated quality standards as proposed by recent recommendations of the World Allergy Organization [61]. In this systematic review, a very low interstudy heterogeneity was found and apparently a not small study effect (the tendency for the intervention effects estimated in smaller studies to differ from those estimated in larger studies due to their lower precision or methodological quality able to influence the results of a meta-analysis) was detected. Statistical heterogeneity, i.e. the variability in the treatment effects evaluated in the different trials, is a consequence of the clinical and/or methodological diversity among the studies. Clinical variation may lead to heterogeneity if the treatment effect is affected by the factors that vary across studies, such as the specific interventions or patient characteristics. Substantial heterogeneity exists when $\mathrm{I}^{2}$ exceeds $50 \%$. In the present meta-analysis, the possible source of heterogeneity may be represented by the different scoring systems used to evaluate the outcomes. For this reason, we utilized the SMD which is a robust measure, not dependent on the measurement scale, providing the effect size of the intervention in SD units.

The analysis of the reported AE revealed no statistically significant differences between the active (fexofenadine) and placebo treatments. In the study by Wahn et al. [46], the frequency of treatment-emergent AE (TEAEs) was similar between the fexofenadine ( 85 of $464,18.3 \%$ ) and placebo (88 of $471,18.7 \%$ ) groups. Three children in the fexofenadine-treated group experienced TEAEs that led to withdrawal from the study, but these were not considered to be related to treatment (asthma, $\mathrm{n}=1$; upper respiratory infection, $\mathrm{n}=1$, and vomiting, $\mathrm{n}=1$ ); 1 child receiving fexofenadine experienced neutropenia, but further investigation revealed this was related to a recent infectious disease.

In the study by Bronsky et al. [47], no statistically significant changes in electrocardiographic parameters (PR, QT, QTc, QRS, or RR intervals) were observed with any dose of fexofenadine or with placebo treatment. In the study by Casale et al. [48], 2 patients discontinued treatment due to an $\mathrm{AE}$ considered possibly related to treatment (for upper respiratory tract infection and somnolence, respectively). No serious AE and no significant clinical changes in heart rate or blood pressure were reported by Van Cauwenberge et al. [13]; the most frequent $\mathrm{AE}$ in that study, i.e. asthenia, diarrhea, nausea, headache, and sedation, were reported with equal frequency in the 2 groups. Headache was the most frequent complaint in the study by Bernstein et al. [49], without significant differences between the active and placebo treatment groups; no changes in electrocardiographic parameters from baseline were found in this study. Howarth et al. [50] reported headache in $7 \%$ of the participants receiving placebo and in $8 \%$ of the patients in the fexofenadine group. Drowsiness was reported by $3 \%$ of patients in both the fexofenadine and placebo groups; the incidence of fatigue was also comparable in the 2 groups, and clear differences in VAS-assessed somnolence across treatments were not found. The overall incidence of AE was similar for all treatment groups in the Schapowal et al. [51] trial, while in the study by Berger et al. [52] 1 was superior in the active treatment group where the most common events were headache, nausea, and somnolence. There were no significant differences in changes in clinical laboratory results and vital signs between the active and control groups in any of the studies included in this analysis.

Summarizing these data, the overall incidence of AE was similar in the active and placebo treatment groups; the most commonly reported AE was headache. No statistically significant changes in electrocardiographic parameters or clinical heart scores related to any dose of fexofenadine were observed. The confirmed efficacy together with the absence of serious $\mathrm{AE}$ and the paucity of bothersome side effects should also impact patients' perspective, although no preference analysis or patient-reported outcome evaluations are currently available. These last 2 considerations should directly impact the risk/benefit ratio in favor of fexofenadine treatment.

Specifically concerning the evidence of benefits and disadvantages related to a pediatric population, our assessment was very cautious as suggested by the GRADE Working Groups. This approach, in fact, gives great importance to the degree of confidence in the estimations through a detailed analysis of the methodology of clinical trials and other factors related to the external validity of the results. Despite the fact that direct evidence comes only from 1 study, our conclusions are optimistic regarding a favorable ratio of benefits to disadvantages using fexofenadine in children; we strongly believe that further research is likely to change the current estimations, most likely reinforcing them.

In conclusion, following the aforementioned criteria for evaluating the degree of confidence in estimations, this study has 5 major strengths: it is the first attempt to evaluate the efficacy and safety of fexofenadine in AR by means of a meta-analysis; it shows consistency between positive results in TSS and individual symptoms; a large 
population was included in the analysis; there was no relevant interstudy heterogeneity, and the good safety profile of fexofenadine was confirmed. All of these values, together with the absence of important limitations, encourage the use of this antihistamine for the treatment of SAR.

\section{Implications for Further Research}

Further long-term evaluations of fexofenadine's efficacy and safety should be conducted in the context of well-designed and rigorous DBPC RCT in patients with both SAR and perennial AR. Focused investigations on populations composed solely of children are required to provide specific recommendations. Also, additional assessments of the effect of fexofenadine on patients' reported outcomes are required.

\section{Acknowledgements}

This study was partially supported by ARMIA (Associazione Ricerca Malattie Immunologiche e Allergiche) and by LIBRA Argentina (Lucha Intergral contra las Broncopatias obstructivas cronicas, Rinitis y Asma).

We are grateful for the unrestricted collaboration of Thomas Casale, David I. Bernstein, and Paul Van Cauwenberge.

\section{References}

1 Bousquet J, Van Cauwenberge P, Khaltaev N, Aria Workshop Group, World Health Organization: Allergic rhinitis and its impact on asthma. J Allergy Clin Immunol 2001; 108(suppl 5):S147-S334.

2 Bielory L: Ocular allergy overview. Immunol Allergy Clin North Am 2008;28:1-23.

-3 Rosenwasser L: New insights into the pathophysiology of allergic rhinitis. Allergy Asthma Proc 2007;28:10-15.

-4 Demoly P, Allaert FA, Lecasble M, Bousquet J, PRAGMA: Validation of the classification of ARIA (allergic rhinitis and its impact on asthma). Allergy 2003;58:672-675.

-5 Canonica GW, Bousquet J, Mullol J, Skadding GK, Virchow JC: A survey of the burden of allergic rhinitis in Europe. Allergy 2007; 62(suppl 85):17-25.

-6 Storms W: Allergic rhinitis-induced nasal congestion: its impact on sleep quality. Prim Care Respir J 2008;17:7-18.

7 Aï-Khaled N, Pearce N, Anderson HR, Ellwood P, Montefort S, Shah J, ISAAC Phase Three Study Group: Global map of the prevalence of symptoms of rhinoconjunctivitis in children: the International Study of Asthma and Allergies in Childhood (ISAAC) Phase Three. Allergy 2009;64:123-148.

$\checkmark 8$ Bousquet J, van Cauwenberge P, Ait Khaled $\mathrm{N}$, Bachert C, Baena-Cagnani CE, Bouchard $\mathrm{J}$, et al: Pharmacologic and anti-IgE treatment of allergic rhinitis ARIA update (in collaboration with GA2LEN). Allergy 2006;61: 1086-1096.

-9 Bousquet J, Bindslev-Jensen C, Canonica GW, Fokkens W, Kim H, Kowalsky M, et al: The ARIA/EAACI criteria for antihistamines: an assessment of the efficacy, safety and pharmacology of desloratadine. Allergy 2004;59(suppl 77):S4-S16.
10 Walsh GM: Anti-inflammatory properties of antihistamines: an update. Clin Exp Allergy Rev 2005;5:21-25.

11 Nathan RA: The pathophysiology, clinical impact, and management of nasal congestion in allergic rhinitis. Clin Ther 2008;30: 573-586.

12 Kerryn S, Blair J: Fexofenadine: a review of its use in the management of seasonal allergic rhinitis and chronic idiopathic urticaria. Drugs 2000;59:301-321.

13 Van Cauwenberge P, Juniper EF, Star Study Investigating Group: Comparison of the efficacy, safety, and quality of life provided by fexofenadine $120 \mathrm{mg}$, loratadine $10 \mathrm{mg}$, and placebo administered once daily for the treatment of seasonal allergic rhinitis. Clin Exp Allergy 2000;30:891-899.

14 Howarth P, Stern M, Roi L, Reynolds R, Bousquet J: Double-blind, placebo controlled study comparing the efficacy and safety of fexofenadine hydrochloride (120 and $180 \mathrm{mg}$ once daily) and cetirizine in seasonal allergic rhinitis. J Allergy Clin Immunol 1999; 104:927-933.

15 Gross GN, Ganster K, Meeves S, Liao Y, Georges GC: A double-blind, randomized comparison of fexofenadine $180 \mathrm{mg}$ versus cetirizine $10 \mathrm{mg}$ : effect on instantaneous symptom score at the 24th hour. Ann Allergy Asthma Immunol 2003;90:125.

16 Hampel F, Ratner P, Mansfield L, Meeves S, Liao Y, Georges G: Fexofenadine hydrochloride, $180 \mathrm{mg}$, exhibits equivalent efficacy to cetirizine, $10 \mathrm{mg}$, with less drowsiness in patients with moderate-to-severe seasonal allergic rhinitis. Ann Allergy Asthma Immunol 2003;91:354-361.

17 Tashiro M, Mochizuki H, Iwabuchi K, Sakurada $\mathrm{Y}$, Itoh $\mathrm{M}$, Watanabe $\mathrm{T}$, et al: Roles of histamine in regulation of arousal and cognition: functional neuroimaging of histamine $\mathrm{H} 1$ receptors in human brain. Life Sci 2002;72:409-414.
18 Mason J, Reynolds R, Rao N: The systemic safety of fexofenadine $\mathrm{HCl}$. Clin Exp Allergy 1999;29(suppl 3):163-170.

19 Baena-Cagnani CE: Safety and tolerability of treatments for allergic rhinitis in children. Drug Saf 2004;27:883-898.

20 Guyatt GH, Oxman AD, Kunz R, Falck-Ytter Y, Vist GE, Liberati A, Schünemann HJ, GRADE Working Group: Going from evidence to recommendations. BMJ 2008;336: 1049-1051.

21 Shekelle PG, Woolf SH, Eccles M, Grimshaw J: Clinical guidelines: developing guidelines. BMJ 1999;318:593-596.

-22 Brozek JL, Baena-Cagnani CE, Bonini S, Canonica GW, Rasi G, van Wijk RG, Zuberbier T, Guyatt G, Bousquet J, Schünemann HJ: Methodology for development of the Allergic Rhinitis and its Impact on Asthma guideline 2008 update. Allergy 2008;63:38-46.

23 Robinson KA, Dickersin K: Development of a highly sensitive search strategy for the retrieval of reports of controlled trials using PubMed. Int J Epidemiol 2002;31:150-153.

24 The Cochrane Collaboration: Cochrane Handbook for Systematic Reviews of Interventions Version 5.0.0. 2008. http://www. cochrane-handbook.org.

25 Dawson B: Research questions about one group; in: Dawson B (ed): Basic and Clinical Biostatistics, ed 4. New York, McGraw-Hill, 2004, p 118

26 Viera AJ, Garrett JM: Understanding interobserver agreement: the kappa statistic. Fam Med 2005;37:360-363.

27 DigitizeIt 1.5.7 program. Braunschweig, Bormann, 2003. 
28 Deeks JJ, Altman D, Bradburn MJ: Statistical methods for examining heterogeneity and combining results from several studies in meta-analysis; in Egger M, Davey Smith G, Altman DG, (eds): Systematic Reviews in Health Care. London, BMJ, 2001, pp 285312.

29 Egger M, Smith GD, Phillips AN: Meta-analysis: principles and procedures. BMJ 1997; 315:1533-1537.

- 30 Higgins JP, Thompson SG, Deeks JJ, Altman DG: Measuring inconsistency in meta-analyses. BMJ 2003;327:557-560.

- 31 Sutton AJ, Higgins JP: Recent developments in meta-analysis. Stat Med 2008;27:625-650.

- 32 Penagos M, Passalacqua G, Compalati E, Baena-Cagnani CE, Orozco S, Pedroza A, Canonica GW: Meta-analysis of the efficacy of sublingual immunotherapy in the treatment of allergic asthma in pediatric patients, 3 to 18 years of age. Chest 2008;133:599-609.

33 Analyses Version 5.0 for Windows. Oxford, The Cochrane Collaboration, 2008.

- 34 Berkowitz RB, Braker S, Lutz C, Jones P, Meeves S, Qiu C, Varghese ST, Georges G: Efficacy of fexofenadine in the prophylactic control of cat allergen-induced allergic rhinitis. Ann Allergy Asthma Immunol 2006; 96:327-333

- 35 Day JH, Briscoe MP, Rafeiro E, Ratz JD, Ellis AK, Frankish CW, Chapman D, deGuia EC, Kramer B, Warner C: Comparative efficacy of cetirizine and fexofenadine for seasonal allergic rhinitis, 5-12 $\mathrm{h}$ postdose, in the environmental exposure unit. Allergy Asthma Proc 2005;26:275-282.

-36 Day JH, Briscoe MP, Rafeiro E, Hewlett D Jr, Chapman D, Kramer B: Randomized double-blind comparison of cetirizine and fexofenadine after pollen challenge in the Environmental Exposure Unit: duration of effect in subjects with seasonal allergic rhinitis. Allergy Asthma Proc 2004;25:59-68.

- 37 Allocco FT, Votypka V, deTineo M, Naclerio RM, Baroody FM: Effects of fexofenadine on the early response to nasal allergen challenge. Ann Allergy Asthma Immunol 2002; 89:578-584.

- 38 Horak F, Zieglmayer PU, Zieglmayer R, Kavina $A$, Lemell $P$ : Levocetirizine has a longer duration of action on improving TNSS than fexofenadine after single administration. $\mathrm{Br}$ J Clin Pharmacol 2005;60:24-31.

- 39 Day JH, Briscoe MP, Welsh A, Smith JN, Clark A, Ellis AK, Mason J: Onset of action, efficacy, and safety of a single dose of fexofenadine hydrochloride for ragweed allergy using an environmental exposure unit. Ann Allergy Asthma Immunol 1997;79:533-540.
40 Lee DK, Gardiner M, Haggart K, Fujihara S, Lipworth BJ: Comparative effects of desloratadine, fexofenadine and levocetirizine on nasal AD challenge in patients with perennial AR. Clin Exp Allergy 2004;34:650-653.

41 Berger WE, Lumry WR, Meltzer EO, Pearlman DS: Efficacy of desloratadine, $5 \mathrm{mg}$, compared with fexofenadine, $180 \mathrm{mg}$, in patients with symptomatic seasonal allergic rhinitis. Allergy Asthma Proc 2006;27:214223.

42 Hyo S, Fujieda S, Kawada R, Kitazawa S, Takenaka $\mathrm{H}$ : The efficacy of short-term administration of 3 antihistamines vs. placebo under natural exposure to Japanese cedar pollen. Ann Allergy Asthma Immunol 2005; 94:457-464.

43 Meltzer EO, Casale TB, Nathan RA, Thompson AK: Once-daily fexofenadine $\mathrm{HCl}$ improves quality of life and reduces work and activity impairment in patients with seasonal allergic rhinitis. Ann Allergy Asthma Immunol 1999;83:311-317.

44 Lee DK, Gray RD, et al: A placebo controlled evaluation of butterbur and fexofenadine on objective and subjective outcomes in perennial allergic rhinitis. Clin Exp Allergy 2004; 34:646.

45 Wilson AM, Haggart K, Sims EJ, Lipworth BJ: Effects of fexofenadine and desloratadine on subjective and objective measures of nasal congestion in seasonal allergic rhinitis. Clin Exp Allergy 2002;32:1504-1509.

46 Wahn U, Meltzer EO, Finn AF Jr, Kowalski ML, Decosta P, Hedlin G, Scheinmann P, Bachert C, Rosado Pinto JE, Baena-Cagnani C, Potter P, Simons FE, Ruuth E: Fexofenadine is efficacious and safe in children (aged 6-11 years) with seasonal allergic rhinitis. J Allergy Clin Immunol 2003;111:763-769.

47 Bronsky EA, Falliers CJ, Kaiser HB, et al: Effectiveness and safety of fexofenadine, a new nonsedating H1-receptor antagonist, in the treatment of fall allergies. Allergy Asthma Proc 1998;19:135-141.

48 Casale TB, Andrade C, Qu R: Safety and efficacy of once-daily fexofenadine $\mathrm{HCl}$ in the treatment of autumn seasonal allergic rhinitis. Allergy Asthma Proc 1999;20:193-198.

49 Bernstein DI, Schoenwetter WF, Nathan RA, et al: Efficacy and safety of fexofenadine hydrochloride for treatment of seasonal allergic rhinitis. Ann Allergy Asthma Immunol 1997;79:443-448.
50 Howarth PH, Stern MA, Roi L, Reynolds R, Bousquet J: Double-blind, placebo-controlled study comparing the efficacy and safety of fexofenadine hydrochloride $(120$ and $180 \mathrm{mg}$ once daily) and cetirizine in seasonal allergic rhinitis. J Allergy Clin Immunol 1999;104:927-933.

-51 Schapowal A, Study Group: Treating intermittent allergic rhinitis: a prospective, randomized, placebo and antihistamine-controlled study of Butterbur extract Ze 339. Phytother Res 2005;19:530-537.

52 Berger W, Lumry W, Meltzer O, et al: Efficacy of desloratadine $5 \mathrm{mg}$, compared to fexofenadine $180 \mathrm{mg}$ in patients with symptomatic allergic rhinitis. Allergy Asthma Proc 2006;27:214-223.

- 53 Egger M, Smith GD, Schneider M, Minder C: Bias in meta-analysis detected by a simple, graphical test. BMJ 1997;315:629-634.

-54 Evidence-Based Medicine Working Group: Evidence-based medicine: a new approach to teaching the practice of medicine. JAMA 1992;268:2420-2425.

55 Bousquet J, Van Cauwenberge P: A critical appraisal of 'evidence-based medicine' in allergy and asthma. Allergy 2004;59(suppl 78):12-20.

56 Sackett DL, Rosenberg WM, Gray JA, et al: Evidence-based medicine: what it is and what it isn't. BMJ 1996;312:71-72.

57 Guyatt GH, Oxman AD, Vist GE, Kunz R, Falck-Ytter Y, Alonso-Coello P, Schünemann HJ, GRADE Working Group: GRADE: an emerging consensus on rating quality of evidence and strength of recommendations. BMJ 2008;336:924-926.

58 Guyatt GH, Oxman AD, Kunz R, Falck-Ytter Y, Vist GE, Liberati A, Schünemann HJ, GRADE Working Group: going from evidence to recommendations. BMJ 2008;336: 1049-1051.

59 Cohen J: Statistical Power Analysis for the Behavioral Sciences, ed 2. New Jersey, Lawrence Erlbaum, 1988.

60 Higgins J, Thompson S, Deeks J, Altman D: Statistical heterogeneity in systematic reviews of clinical trials: a critical appraisal of guidelines and practice. J Health Serv Res Policy 2002;7:51-61

61 Canonica GW, Baena-Cagnani CE, Bousquet J, Bousquet PJ, Lockey RF, Malling HJ, Passalacqua G, Potter P, Valovirta E: Recommendations for standardization of clinical trials with allergen specific immunotherapy for respiratory allergy: a statement of a World Allergy Organization (WAO) taskforce. Allergy 2007;62:317-324. 